\title{
Avaliação ambiental do ciclo de vida de telhas de fibrocimento com fibras de amianto ou com fibras de polipropileno
}

\author{
Environmental assessment of the life cycle of cementitius \\ roofing sheets with asbestos fibers or with polypropylene \\ fibers
}

\section{Vinicius Martins Marques \\ Luciana Paulo Gomes \\ Andrea Parisi Kern}

\section{Resumo}

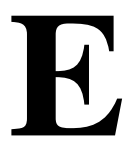

ste trabalho teve por objetivo avaliar o ciclo de vida de telhas de fibrocimento fabricadas com fibras de amianto ou com fibras de polipropileno. Foram utilizadas as técnicas de Avaliação do Ciclo de Vida (ACV) e de Levantamento de Aspectos e Impactos Ambientais (Laia) para analisar comparativamente os impactos ambientais causados. Na ACV determinaram-se, para todas as etapas, as emissões atmosféricas causadoras do efeito estufa, da chuva ácida e as que possuem toxicidade humana, além do consumo de insumos (água e energia). No Laia agregaram-se à ACV os impactos de utilização de recursos naturais e os riscos à saúde devido aos fatores prejudiciais dos materiais constituintes das telhas. Foram avaliados dois cenários, onde se fixaram os locais de extração de matéria-prima, o local da obra e o aterro industrial para o qual seriam levados os resíduos das telhas após a vida útil deles, variando-se apenas os locais de fabricação das telhas. O cenário que empregou fibras de polipropileno foi mais vantajoso ambientalmente em quatro categorias entre as sete avaliadas, confirmando assim, com essa avaliação, que o uso de amianto é mais desfavorável que o uso de polipropileno sob o foco ambiental.

Palavras-chaves: Resíduos de construção e demolição. Amianto. Telhas de fibrocimento. Aspectos e impactos ambientais. Ciclo de vida.

\begin{abstract}
The aim of this study is to evaluate the life cycle of cementitious roofing sheets manufactured with asbestos fibres or with polypropylene fibres. The Life Cycle Assessment (LCA) technique and the Assessment of Aspects and Environmental Impacts (AAIE) technique were applied to make a comparative analysis of the environmental impacts caused. In the LCA technique, the atmospheric emissions that cause the greenhouse effect, acid rain and emissions with human toxicity potential, as well as the consumption of

resources (water and energy) were determined for all the stages of the life cycle. In the AAIE technique, the impacts on the use of natural resources and the health risks due the carcinogen factors of the constituent materials of the roofing sheets were added to the LCA assessment. Two scenarios were then evaluated, in which the raw material extraction location, the location of the construction site where the roof sheets would be used and the destination of the waste after its life cycle were fixed, but the production locations varied. As a final result, the scenario with polypropylene fibres had a better evaluation in four out of the seven categories analysed. Thus, this study confirms that, from an environmental perspective, the use of asbestos fibres is more unfavourable than the use of polypropylene fibres.
\end{abstract}

Vinicius Martins Marques Universidade do Vale do Rio dos Sinos São Leopoldo - RS - Brasil

Luciana Paulo Gomes Universidade do Vale do Rio dos Sinos São Leopoldo - RS - Brasil

Andrea Parisi Kern Universidade do Vale do Rio dos Sinos São Leopoldo - RS - Brasil

Recebido em 12/11/14 Aceito em 21/09/15
Keywords: Construction and demolition waste. Asbestos. Roofing sheets. Aspects and environmental impacts. Life cycle assessment.

MARQUES, V. M.; GOMES, L. P.; KERN, A. P. Avaliação ambiental do ciclo de vida de telhas de fibrocimento 


\section{Introdução}

O setor da indústria da construção civil é um indicador fiel quando se deseja mensurar o crescimento da economia de um país, ou seja, quando o cenário econômico é positivo, a construção civil tende a expandir-se. A construção civil é o setor responsável por promover toda a infraestrutura necessária para suprir as necessidades da sociedade, passando pela geração de energia, saneamento básico, transportes e evidentemente pela moradia (AGOPYAN; JOHN, 2011). A contrapartida desse fato é que, para suprir toda a demanda, o setor é responsável por uma parcela significativa no consumo de recursos naturais e geração de resíduos sólidos de construção e demolição (RCD). Como em todo crescimento industrial, a utilização de insumos gera resíduos, que necessitam ser gerenciados.

Em 2002 foi aprovada a Resolução n ${ }^{\circ}$ 307, que tem como objetivos reduzir os impactos ambientais originados na construção civil e responsabilizar os geradores de resíduos quanto a sua destinação final (CONSELHO..., 2002). Essa resolução indica também que os geradores devem ter por objetivo prioritário a não geração de resíduos, e caso não seja possível o objetivo secundário deve ser a redução, a reutilização, a reciclagem e, por fim, sua destinação final.

Em paralelo a essas regulamentações foi publicada em 2010 a Lei federal $n^{\circ} 12.305$ (BRASIL, 2010), que institui a Política Nacional de Resíduos Sólidos, a qual tem por objetivos diagnosticar a situação atual dos resíduos sólidos e estabelecer metas de redução, reciclagem e reaproveitamento energético, e sobretudo metas referentes à eliminação dos lixões, entre outras ações mitigadoras no intuito de regulamentar o setor (BRASIL, 2010).

Por outro lado, a Europa tem uma preocupação maior no quesito reciclabilidade dos resíduos de construção e demolição, e alguns países reciclam quase a totalidade de resíduos (VAZQUEZ, 2001). Segundo Ortiz, Pasqualino e Castells (2010), na União Europeia aproximadamente $75 \%$ do RCD gerado é destinado a aterros. Entretanto, a Holanda, país com pouca disponibilidade de recursos naturais e com grande demanda de materiais de construção, vem procurando aumentar a eficiência do processo de reciclagem de resíduos, preocupada para que no futuro não haja um colapso da indústria de extração de minérios. Os países vizinhos, como Dinamarca e Bélgica, já alcançaram índices de reciclagem de mais de $80 \%$ de seus resíduos de construção e demolição, enquanto em países como Portugal e Espanha esse percentual não chega a $40 \%$ do total (ORTIZ; PASQUALINO; CASTELLS, 2010).

Já no Brasil ainda é pequena ou quase inexistente a utilização de materiais reciclados na fabricação de componentes da construção civil, embora haja grande disponibilidade de material com potencial de ser reciclado; este material, quase em sua totalidade, é utilizado essencialmente em sub-bases de vias e rodovias, fato que demonstra a despreocupação com o tema, corroborando a ideia de que o problema da escassez dos recursos naturais, aparentemente, não afeta o país (VIEIRA, 2003). Ainda, segundo estudo de Miranda, Angulo e Careli (2009), em 2008 cerca de 1\% das empresas construtoras no Brasil possuía parcerias com empresas de consultoria e outras instituições conhecidas para a implantação do gerenciamento de RCD em seus canteiros.

Entre as classes discriminadas na Resolução no 307 (CONSELHO..., 2002) a que causa maior preocupação é a Classe $\mathrm{D}$, em que estão os resíduos classificados como perigosos e capazes de causar riscos à saúde humana ou ao meio ambiente, se gerenciados de forma inadequada. Um deles é o amianto, ou asbesto como é chamado, que tem o nome de origem latina amianthus, que significa "incorruptível", e também do grego, asbesto, que quer dizer "o que não pode ser destruído pelo fogo", fato que já demonstra suas principais características: suportar altas temperaturas e não sofrer alteração química nessas condições. Essas características são interessantes para a indústria, e o amianto popularizou-se no período pós-Revolução Industrial como uma matéria-prima excelente para isolamentos térmicos das máquinas a vapor (ASSOCIAÇÃO BRASILEIRA DOS EXPOSTOS AO AMIANTO, 2013).

Desde 1940 o amianto é explorado legalmente no Brasil, e estima-se que sua produção seja da ordem de 200.000 toneladas por ano. Acredita-se que cerca de 10.000 trabalhadores já teriam se contaminado com o material na atividade de mineração, porém alguns jornais e revistas já divulgaram a informação de que cerca de 200.000 a 300.000 pessoas foram expostas ao material, incluídas as fases de extração e manejo do material (TERRA FILHO; BAGATIN, 2010).

Além das vantagens já citadas de resistência à tração e a altas temperaturas, o amianto possui várias outras características, tais como baixa condutividade térmica, resistência a microorganismos e a produtos químicos, elevada resistência dielétrica, excelente isolamento elétrico 
e acústico, alta durabilidade, flexibilidade, estabilidade em diferentes valores de $\mathrm{pH}$, fácil manuseio para ser tecido ou fiado, boa interação com a água e afinidade com o cimento, resinas e ligantes (SCLIAR, 1998; FAUSTINO, 2013; HUET, 2013).

Essas mesmas características são as principais responsáveis por seu poder cancerígeno, fato que levou 58 países a proibirem sua utilização, sendo pioneiras na ação a Islândia, em 1983, e a Noruega, em 1984. Outra data que merece destaque foi a do banimento total do amianto nos países da Comunidade Europeia, a partir de janeiro de 2005 .

A exposição a fibras de amianto maiores ou iguais a $5 \mu \mathrm{m}$ de comprimento é internacionalmente considerada como aquela de potencial patogênico respiratório definido, tanto para condições não malignas (placas pleurais e asbestose) como malignas (mesotelioma e câncer de pulmão) (HEALTH..., 1991). Porém, estudos demonstram que as doenças do amianto levam 20, 30 ou até 40 anos para se manifestar (COMISSÃO..., 2013). É consenso na área médica que todas as doenças originadas do amianto são progressivas e incuráveis. Mesmo que a pessoa que foi exposta ou inalou a poeira seja afastada da fonte do problema, a doença continua evoluindo progressivamente e com frequência leva à morte (MENDES, 2001).

Com base nesses dados, em 2001 cinco estados brasileiros sancionaram leis estipulando diversas datas de proibição progressiva sobre diversos setores em relação ao uso do amianto. Já no ano de 2003 o Supremo Tribunal Federal (STF) revogou as leis, citando como argumento que as disposições delas invadiam a competência legislativa da União relativa a normas gerais de produção, consumo e proteção ao meio ambiente. Porém, até os dias atuais não se formulou nenhuma lei federal que complemente a abordagem das leis revogadas.

O cenário envolvendo os resíduos de materiais contendo amianto é polêmico, pois ao mesmo tempo em que a literatura médica dá exemplos e indica que a melhor solução seria seu banimento, o setor de engenharia e pesquisa de materiais ainda não definiu um único material ou uma combinação de diversos que possam ser padronizados oficialmente como seus substitutos, atendendo a todas as características que o amianto possui, agregando menores índices de periculosidade e suprindo a demanda de produtos dessa natureza.

A busca por materiais que possam substituir o amianto já existe desde meados da década de 1970 , fato comprovado pelo estudo de PYE (1979), o qual apresenta diversos materiais que poderiam ser utilizados como alternativos ao amianto, tais como ligas de alumínio e silício, politetrafluoretileno, fibra de vidro e a vermiculita associada ao amianto, esta última opção como forma de minimizar o uso deste.

Atualmente já se encontram no mercado produtos de fibrocimento sem amianto. Conforme relatório elaborado no intuito de encontrar algum substituto para o amianto, inúmeros materiais estão sendo utilizados em produtos, entre eles silicato de cálcio, fibra de carbono, fibra de celulose, fibra cerâmica, fibra de vidro, fibra de aço e algumas fibras orgânicas tais como aramida, polietileno, polipropileno e politetrafluoretileno (UNITED..., 2013).

Com relação à fabricação de telhas de fibrocimento no Brasil existem diversas empresas que utilizam ou não o amianto em suas composições. Um dos materiais alternativos encontrados pelo setor, em meados da década de 1990, inicialmente foi a fibra sintética alternativa de PVA (poli álcool vinílico), que posteriormente, em 2003, foi substituída por determinados fabricantes pela fibra de polipropileno (PP) na produção de telhas e caixas d'água.

No Brasil existe uma única mina de amianto crisotila, a qual está em operação e responde pela totalidade da produção nacional. Trata-se da mina de Cana Brava, localizada no município de Minaçu, no Estado de Goiás (TERRA FILHO; BAGATIN, 2010).

Como forma de avaliar e comparar diferentes processos produtivos de telhas de fibrocimento, decidiu-se por utilizar uma das ferramentas que têm mostrado bom desempenho na tomada de decisões, que é a Avaliação do Ciclo de Vida (ACV). Essa ferramenta deve ser elaborada considerando-se todas as etapas que fazem parte do processo, desde a etapa de extração das matérias-primas (berço do processo) até seu uso final (túmulo ou fím do ciclo). Melhor ainda se forem incorporadas ao processo técnicas de reciclagem, as quais transformam o produto após o uso em matéria-prima novamente (volta ao berço), sendo nominadas como berço ao túmulo (cradleto-grave) ou berço ao berço (cradle-to-cradle).

A ACV é regulada por normas da série ISO 14000. No Brasil os princípios gerais e as etapas de definição de objetivos e escopo além da análise do inventário são abordados na NBR ISO 14040 (ABNT, 2009a). Ainda, a abordagem da avaliação de impactos ambientais aliada com a interpretação do ciclo de vida é determinada pela NBR ISO 14044 (ABNT, 2009b). Além destas já citadas, as normas brasileiras são complementadas pela legislação internacional, e pode-se destacar a 
ISO/TR 14047 (INTERNATIONAL..., 2012a), que oferece exemplos de aplicação, a ISO/TS 14048 (INTERNATIONAL..., 2002), que estabelece o formato de apresentação de dados, e a ISO/TR 14049 (INTERNATIONAL..., 2012b), que exemplifica especificamente quanto à definição de objetivos.

A ACV se divide em quatro etapas: definição de objetivo e escopo, em que se definem a abrangência, os limites do trabalho, a metodologia e a unidade funcional; análise do inventário, fase na qual são coletadas as informações; avaliação dos impactos, em que se estipulam indicadores que possam contribuir para a avaliação das informações; e interpretação, etapa que ocorre durante todo o processo, ao fim de qualquer etapa anterior, que tem por função corrigir falhas eventuais e obter conclusões e recomendações sobre o estudo abordado.

Outro exemplo de ferramenta de avaliação ambiental é a técnica de Levantamento de Aspectos e Impactos Ambientais (Laia). Tal instrumento, amparado pela NBR 14001 (ABNT, 2004), tem como ponto forte o fato de buscar a "melhoria contínua", permitindo alcançar objetivos ambientais e econômicos. Dessa forma, essa técnica de avaliação ambiental se torna completa, pois não se limita a avaliar as entradas e saídas do ciclo de vida de processos e produtos, mas também analisa a periculosidade dos materiais envolvidos no processo analisado, fato que é de interesse específico neste trabalho.

Desse modo, o objetivo geral deste trabalho foi o de levantar os aspectos e impactos ambientais gerados no ciclo de vida de materiais de construção usados em telhas de fibrocimento que utilizam ou não fibras de amianto em sua composição. Como objetivo específico, foi realizar a comparação por meio da ACV e do Laia dos processos de extração, fabricação, uso e descarte de telhas de fibrocimento que empregam amianto ou fibras de polipropileno.

\section{Metodologia}

\section{Escopo}

O trabalho foi realizado baseando-se em obras localizadas no município de Novo Hamburgo, RS. Foram avaliados dois cenários, onde se fixaram os locais de extração de matéria-prima, o local da obra e o aterro industrial para o qual seriam levados os resíduos das telhas após a vida útil deles, variando-se apenas os locais de fabricação das telhas: a telha sem amianto é fabricada em Esteio, RS, e a telha com amianto é fabricada em Colombo, PR. Esses locais foram escolhidos porque são os locais de fabricação das telhas mais próximos do local da obra. Dessa forma, conforme Marques (2014), minimiza-se o efeito das etapas de transporte na avaliação ambiental. Grandes distâncias percorridas entre os locais de extração de matéria-prima e a fábrica e/ou desta até o local de uso das telhas resultaram em avaliações ambientais desbalanceadas, indicando que as emissões geradas nessas etapas são mais impactantes do que o processo de fabricação em si das telhas com o uso de diferentes fibras, foco deste trabalho. Para cada cenário foi determinada a geração de emissões gasosas, e também se avaliou o consumo de energia e água.

A unidade funcional (UF) neste trabalho foi escolhida como sendo um pallet de 60 telhas de fibrocimento com dimensões de $92 \mathrm{~cm}$ x $213 \mathrm{~cm} \mathrm{e}$ espessura de $6 \mathrm{~mm}$. Conforme orientações dos fabricantes, telhados que utilizam esse tipo de cobertura devem prever o transpasse entre as telhas, diminuindo assim a área útil de cada telha de $92 \mathrm{~cm}$ x $213 \mathrm{~cm}$ para $87 \mathrm{~cm} \times 198 \mathrm{~cm}$. Portanto, cada telha teve uma área útil calculada em $1,72 \mathrm{~m}^{2}$, e como a unidade funcional adotada foi de um pallet de 60 telhas, a unidade funcional foi dimensionada para uma área de 103,2 $\mathrm{m}^{2}$, suficiente para cobrir uma área aproximada de 100 $\mathrm{m}^{2}$.

\section{Análise do inventário}

Utilizaram-se informações disponibilizadas nos sites das duas empresas fabricantes de telhas (www.eternit.com.br e www.brasilit.com.br) e sites de empresas fabricantes das matérias-primas das telhas (www.abcp.org.br e www.vcimentos.com.br), de forma a obterem-se dados do tipo composição e tamanho das telhas, emissões atmosféricas na fabricação das matériasprimas, principalmente o cimento, e localização das fábricas.

Como os fabricantes não disponibilizaram a composição das telhas, decidiu-se por aplicar os mesmos valores encontrados por Frazão e Fernandes (2004) para a unidade funcional deste trabalho, conforme mostra a Tabela 1.

Conforme observado no Quadro 1, o autor não cita a presença de água na composição das telhas. Porém, ele argumenta que ela é mínima, devido ao processo de secagem em estufa.

No inventário, além dos valores anteriores (Tabela 1), foi elaborado um diagrama de blocos, composto das etapas de extração das matériasprimas, transporte até a fábrica, fabricação da telha de fibrocimento, transporte até a obra, uso da telha, transporte para o aterro e destinação final. $\mathrm{O}$ diagrama de blocos é apresentado na Figura 1.

190 Marques, V. M.; Gomes, L. P.; Kern, A. P. 
Tabela 1 - Composição das telhas para a unidade funcional

\begin{tabular}{c|r|r|c|r|r}
\hline \multicolumn{2}{c}{ Cenário 1: TELHA COM AMIANTO } & \multicolumn{3}{c}{ Cenário 2: TELHA COM POLIPROPILENO } \\
\hline Material & {$[\mathbf{k g}]$} & \multicolumn{1}{c}{$\%$} & Material & {$[\mathbf{k g}]$} & \% \\
\hline Cimento hidratado & $1.015,0$ & 80,55 & Cimento hidratado & $1.115,0$ & 87,58 \\
Amianto & 160,0 & 12,70 & Polipropileno (PP) & 28,0 & 2,20 \\
Celulose & 5,0 & 0,40 & Carbonato de cálcio & 14,9 & 1,17 \\
Cinza volante & 47,0 & 3,73 & Celulose & 35,0 & 2,75 \\
Enchimento (Areia) & 33,0 & 2,62 & Cinza volante & 3,5 & 0,27 \\
& & & Sílica amorfa & 73,5 & 5,78 \\
& & & Fita de segurança & 2,6 & 0,20 \\
& & & Floculante & 0,3 & 0,02 \\
& & & Agente antiespumante & 0,4 & 0,03 \\
\hline TOTAL & $1.260,0$ & 100 & TOTAL & $1.273,2$ & 100 \\
\hline
\end{tabular}

Fonte: adaptado de Frazão e Fernandes (2004).

Figura 1 - Diagrama de blocos contendo todas as etapas do ciclo de vida do material

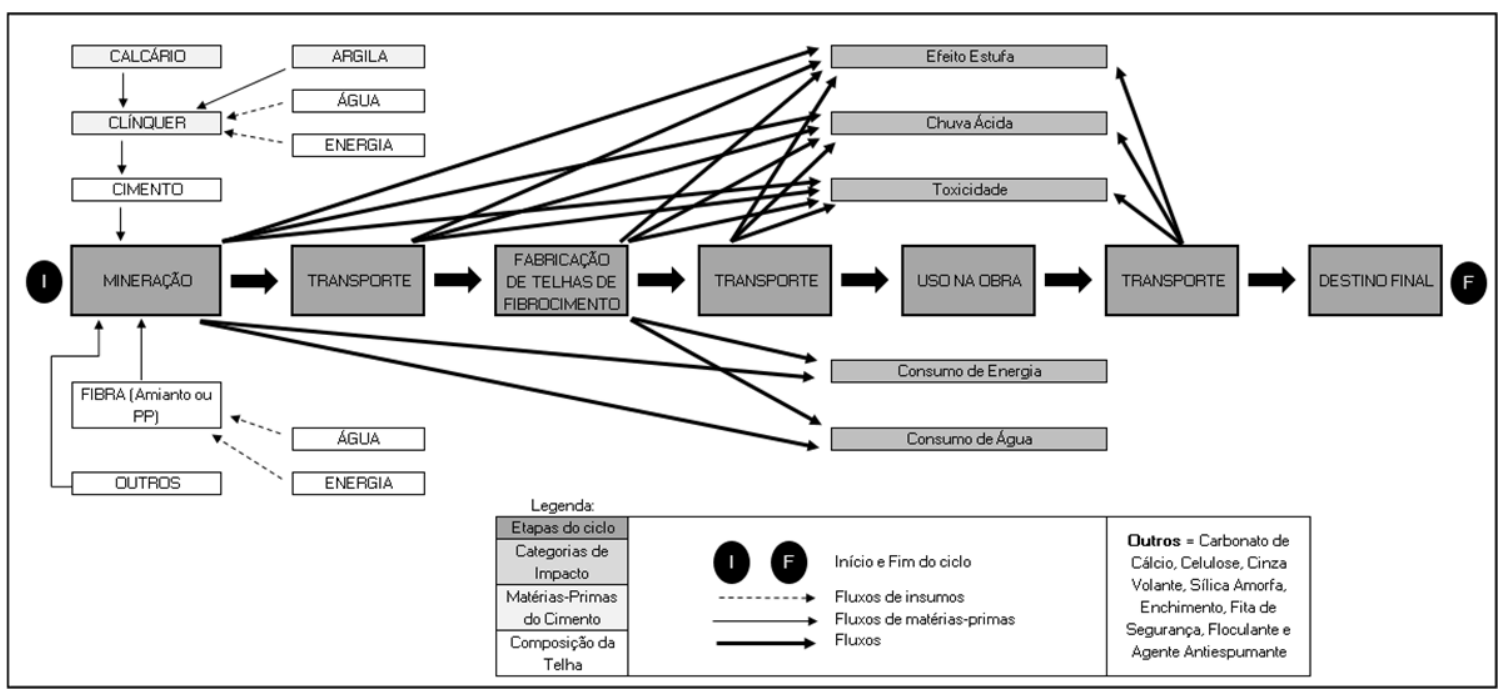

Franco et al. (2013), China (2010), Chen et al. (2007), Costa (2001) e Hausberger et al. (2005) citam que as emissões gasosas mais significativas são monóxido de carbono ( $\mathrm{CO})$, dióxido de carbono $\left(\mathrm{CO}_{2}\right)$, hidrocarbonetos $(\mathrm{HC})$, nitratos em geral $\left(\mathrm{NO}_{\mathrm{X}}\right)$, sulfatos em geral $\left(\mathrm{SO}_{\mathrm{X}}\right)$ e material particulado (MP). Sendo assim, a geração dessas emissões foi quantificada em todas as etapas do ciclo de vida do material. Além dessas emissões, os consumos de água e energia incorporada no processo são de suma importância, se for considerada a escassez de locais apropriados para destinação dos resíduos, bem como o fato de a água ser um insumo não renovável (CLAUDINO; TALAMINI, 2013). Os valores referentes à fase de transporte estão apresentados na Tabela 2.

A etapa de transporte contempla a ligação entre matérias-primas e a fábrica das telhas de fibrocimento, a ligação entre a fábrica e a obra em
Novo Hamburgo, e a ligação entre a obra e o aterro industrial para o qual seriam levados os resíduos após a vida útil, estimada em 50 anos.

Para obter os resultados finais e avaliar os cenários perante as categorias de impacto adotadas, utilizaram-se para cada tipo de emissão os valores equivalentes em $\mathrm{CO}_{2}$ para as emissões que afetam o efeito estufa, adotados por Forster et al. (2007); os valores equivalentes em $\mathrm{SO}_{2}$ para as emissões que têm influência sob a chuva ácida, descritos por GHK Holding Limited (2006); os valores equivalentes de tolueno $\left(\mathrm{C}_{7} \mathrm{H}_{8}\right)$, estabelecidos por Hertwich et al. (2006), para as emissões que possuem alguma toxicidade humana; e os valores unitários de consumo de energia, calculados utilizando-se a unidade de quilowatt-hora (kWh) e o consumo de água, medido por meio da unidade de volume em metros cúbicos $\left(\mathrm{m}^{3}\right)$, como é demonstrado na Tabela 3. 


\section{Avaliação dos impactos}

Adotaram-se cinco categorias de impactos ambientais: efeito estufa, chuva ácida, toxicidade humana, consumo de energia e consumo de água.

\section{Interpretação dos resultados}

Os resultados foram avaliados perante as técnicas de ACV e de Levantamento de Aspectos e Impactos Ambientais, que, além dos critérios avaliados na ACV, também considerou o uso de recursos não renováveis e os riscos à saúde envolvidos na utilização do amianto.

\section{Resultados}

$\mathrm{Na}$ fase de extração de matérias-primas, identificou-se que o cimento e o polipropileno necessitam de processos industriais para fabricação, o que não ocorre com o amianto, que é um produto extraído da natureza e utilizado após etapas de britagem e aspiração das fibras. Na Tabela 4 encontram-se os valores referentes a duas outras etapas: extração das matérias-primas (calcário e argila) e fabricação do cimento.

Já no caso do amianto na etapa de mineração as emissões atmosféricas não estão presentes, pelo fato de não haver necessidade de envolver processos químicos, apenas energia incorporada na utilização das máquinas que efetuam a extração e o material particulado pela presença de poeira (FRAZÃO; FERNANDES, 2004). Os dados estão presentes na Tabela 5.

Tabela 2 - Emissões na fase de transporte dos materiais e produtos

\begin{tabular}{c|c}
\hline EMISSÃO/CONSUMO & VALOR ADOTADO: [kg] EMISSÕES/[km] GASTOS \\
\hline $\mathrm{CO}$ & 0,006 \\
$\mathrm{CO}_{2}$ & 0,288 \\
$\mathrm{HC}$ & 0,003 \\
$\mathrm{NO}_{\mathrm{X}}$ & 0,021 \\
$\mathrm{SO}_{\mathrm{X}}$ & 0,001 \\
$\mathrm{MP}$ & 0,001 \\
Água & 0,000 \\
Energia & 0,000 \\
\hline
\end{tabular}

Fonte: Hausberger et al. (2005).

Tabela 3 - Comparativos em equivalência de $\mathrm{CO}_{2}$

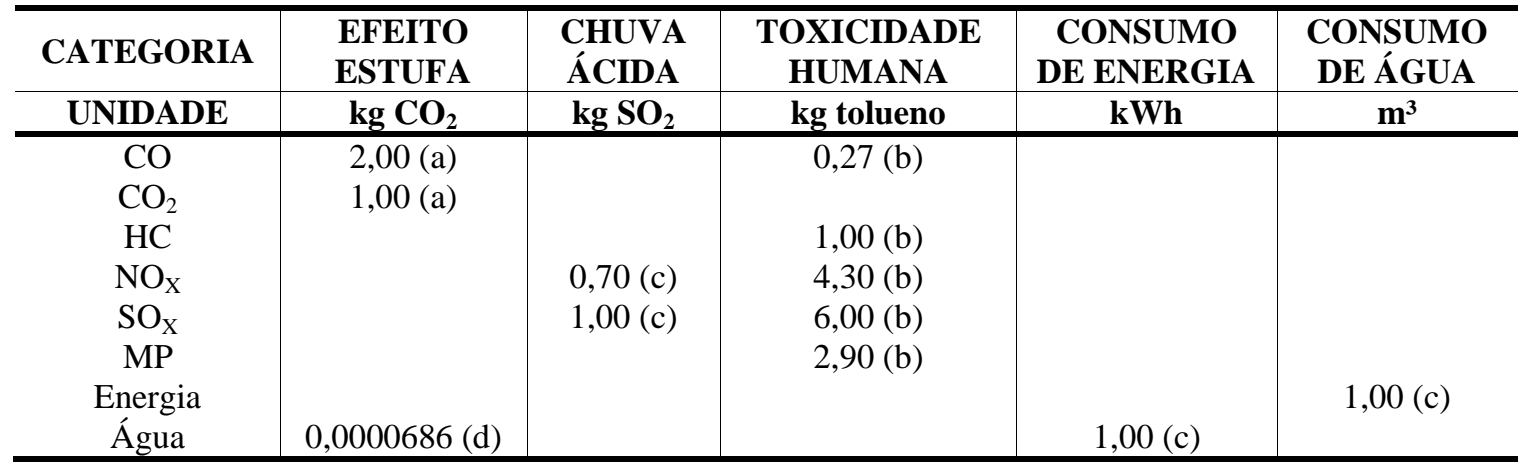

Nota: Legenda:
(a) Forster et al. (2007);
(b) Hertwich et al. (2006);
(c) GHK Holding Limited (2006); e
(d) Companhia Energética de Minas Gerais (2013). 
Tabela 4 - Emissões na fase de mineração das matérias-primas e fabricação do cimento

\begin{tabular}{c|c|c|c}
\hline EMISSÃO/CONSUMO & $\begin{array}{c}\text { UNIDADE/1.000 kg } \\
\text { DE CLÍNQUER }\end{array}$ & UNIDADE & FONTE \\
\hline $\mathrm{CO}$ & 0,000 & {$[\mathrm{~kg}]$} & (TOSTA; SOUZA; SILVA, 2007) \\
$\mathrm{CO}_{2}$ & 659,000 & {$[\mathrm{~kg}]$} & (LIMA, 2010) \\
$\mathrm{HC}$ & 0,000 & {$[\mathrm{~kg}]$} & (TOSTA; SOUZA; SILVA, 2007) \\
$\mathrm{NOx}$ & 1,910 & {$[\mathrm{~kg}]$} & (VCIMENTOS, 2013) \\
$\mathrm{SOx}$ & 1,250 & {$[\mathrm{~kg}]$} & (VCIMENTOS, 2013) \\
$\mathrm{MP}$ & 0,260 & {$[\mathrm{~kg}]$} & (VCIMENTOS, 2013) \\
Água & 100,000 & {$[\mathrm{~L}]$} & (ASSOCIAÇÃO BRASILEIRA DO \\
Energia & 110,000 & {$[\mathrm{kWh}]$} & CIMENTO PORTLAND, 2013) \\
& \multicolumn{2}{|c}{ (MADLOOL et al., 2011) } \\
\hline
\end{tabular}

Tabela 5 - Emissões na fase de mineração do amianto (Cenário 1)

\begin{tabular}{c|c|c}
\hline EMISSÃ O/CONSUMO & UNIDADE/1.000 kg DE AMIANTO & UNIDADE \\
\hline $\mathrm{CO}$ & 0 & {$[\mathrm{~kg}]$} \\
$\mathrm{CO}_{2}$ & 0 & {$[\mathrm{~kg}]$} \\
$\mathrm{HC}$ & 0 & {$[\mathrm{~kg}]$} \\
$\mathrm{NOx}$ & 0 & {$[\mathrm{~kg}]$} \\
$\mathrm{SOx}$ & 0 & {$[\mathrm{~kg}]$} \\
$\mathrm{MP}$ & 0,006 & {$[\mathrm{~kg}]$} \\
Água & 0 & {$[\mathrm{~L}]$} \\
Energia & $1.928,904$ & {$[\mathrm{kWh}]$} \\
\hline
\end{tabular}

Fonte: Frazão e Fernandes (2004).

Especificamente se tratando do polipropileno (PP), que é produzido através da polimerização do monômero propeno, que por sua vez é originado do petróleo, existem altos índices de emissões e consumo de energia, justamente pelo fato de haver em sua fabricação processos químicos envolvidos. De acordo com a PlasticsEurope (2008), durante o processo de fabricação do polipropileno, inúmeras emissões atmosféricas são geradas, causando impactos ambientais como efeito estufa, diminuição da camada de ozônio, acidificação (chuva ácida), formação de ozônio a baixas altitudes e potencial de eutrofização. Esses impactos ambientais são quantificados de acordo com unidades equivalentes para cada categoria de impacto gerado: CFC-11 (triclorofluormetano) equivalente, na categoria diminuição da camada de ozônio; eteno equivalente, na categoria formação de ozônio a baixas altitudes; e fosfato equivalente, na categoria potencial de eutrofização.

Adams et al. (1999) citam que o processo de fabricação do PP emite compostos orgânicos voláteis (COV), aldeídos (formaldeído, propenal, etanal, propanal, butanal e benzaldeído), cetonas (dimetilcetona e butanona) e ácidos orgânicos (ácido fórmico, ácido acético e ácido acrílico). Xiang et al. (2002) apresentam as emissões durante o processo de reaquecimento do PP, contudo quantificaram apenas emissões classificadas como COV, expressando os resultados finais do estudo como número total de COV emitidos em cada ciclo de aquecimento do PP.

Empregou-se a base de dados Ecoinvent, existente em diversos softwares, para obterem-se os valores referentes a emissões atmosféricas e consumo de água e energia na etapa de fabricação do PP. A base Ecoinvent, organizada pela Swiss Centre for Life Cycle Inventories, associação sem fins lucrativos da Suíça, é acessada por diversos pesquisadores, para uso em diferentes áreas de atuação (CAMARGO, 2007; GARCIA; SPERLING, 2010; SILVA; ESTRELA, 2011; NEIVA; MATEUS; BRAGANÇA, 2012; ARAUJO, 2013; PASCUAL-GONZÁLEZ et al., 2015). Os dados referentes à etapa de fabricação do PP na base Ecoinvent estão apresentados na Tabela 6.

Para efeito de cálculo, considerou-se apenas o processo de fabricação dos principais materiais constituintes das telhas, ou seja, o cimento e as fibras utilizadas, amianto e polipropileno, desconsiderando, portanto, o restante dos materiais citados na Tabela 1 .

Levando em consideração esse fato, foram determinadas as distâncias de transporte entre a fase de mineração ou fabricação das matériasprimas e a fábrica de telhas de fibrocimento. Os locais de fabricação do cimento foram 
determinados pela distância da fábrica mais próxima, em Nova Santa Rita, RS, na fabricação de telhas, em Esteio, RS, e em Rio Branco, PR, para a fábrica de Colombo, PR. As distâncias foram calculadas através do site http://br.distanciacidades.com e estão discriminadas na Tabela 7

Por meio de entrevistas presenciais e contatos telefônicos com as fabricantes, determinou-se que na etapa de fabricação o processo utilizado para secagem das telhas é baseado em caldeiras a lenha. Desse modo, para avaliação da etapa de fabricação das telhas e devido à dificuldade na obtenção de dados com os fabricantes, buscou-se na literatura trabalhos que relacionassem emissões atmosféricas com o tipo de caldeira utilizado nas fábricas. Assim, utilizou-se o trabalho de Nascimento (2007), que quantificou o consumo médio de caldeiras desse tipo em $600 \mathrm{~m}^{3}$ de lenha por mês.
Conforme o estudo elaborado pela Cetesb (COMPANHIA..., 2009), para cada metro cúbico de lenha utilizada são gerados aproximadamente $0,827 \mathrm{~kg}$ de $\mathrm{CO}_{2}, 0,017 \mathrm{~kg}$ de $\mathrm{CO}, 0,063 \mathrm{~kg}$ de $\mathrm{HC}, 0,429 \mathrm{~kg}$ de $\mathrm{NO}_{\mathrm{X}}, 0,021 \mathrm{~kg}$ de $\mathrm{SO}_{\mathrm{X}}$ e $2,514 \mathrm{~kg}$ de MP. Esses valores foram multiplicados por 600 $\mathrm{m}^{3}$ de lenha para a obtenção dos valores mensais de geração de emissões e posteriormente foram divididos pela produção mensal das fábricas, para a obtenção do valor de geração por cada unidade funcional, demonstrado nas Tabelas 8 e 9 .

As etapas de uso na obra e destinação final não tiveram valores calculados, pois nessas etapas os processos são manuais e não geram nenhum tipo de emissão atmosférica.

$\mathrm{Na}$ Tabela 10 e 11 são apresentados os valores referentes ao Cenário 1, que aborda a fabricação de telhas com amianto em Colombo.

Tabela 6 - Emissões na fase de fabricação do polipropileno (Cenário 2)

\begin{tabular}{c|c|c}
\hline EMISSÃO/CONSUMO & UNIDADE/1.000 kg DE FIBRA & UNIDADE \\
\hline $\mathrm{CO}$ & 0,025 & {$[\mathrm{~kg}]$} \\
$\mathrm{CO}_{2}$ & $1.663,200$ & {$[\mathrm{~kg}]$} \\
$\mathrm{HC}$ & 0,099 & {$[\mathrm{~kg}]$} \\
$\mathrm{NOx}$ & 3,287 & {$[\mathrm{~kg}]$} \\
$\mathrm{SOx}$ & 0,000 & {$[\mathrm{~kg}]$} \\
$\mathrm{MP}$ & 0,594 & {$[\mathrm{~kg}]$} \\
Água & 594,441 & {$[\mathrm{~L}]$} \\
Energia & 133,014 & {$[\mathrm{kWh}]$} \\
\hline
\end{tabular}

Fonte: Ecoinvent Centre (2013).

Tabela 7 - Distâncias entre as matérias-primas e as fábricas

\begin{tabular}{c|c|c|c}
\hline \multirow{2}{*}{ DISTÂNCIAS DE TRANSPORTE (km) } & \multicolumn{2}{c}{ FÁBRICAS } \\
\cline { 2 - 4 } & Fsteio (RS) & Colombo (PR) \\
\hline \multirow{3}{*}{$\begin{array}{c}\text { Matérias } \\
\text {-primas }\end{array}$} & Fábrica de Cimento & 15 & 240 \\
\cline { 2 - 4 } & Amianto (Minaçu-GO) & 1.235 & 494 \\
\cline { 2 - 4 } & Amolipropileno (Jacareí-SP) & 2.274 & 1.724 \\
\hline
\end{tabular}

Tabela 8 - Emissões na fase de fabricação das telhas de fibrocimento com amianto (Cenário 1)

\begin{tabular}{c|c|c|c|c}
\hline EMISSÃO/CONSUMO & VALOR MENSAL & UNIDADE & UNIDADE/UF & FONTE \\
\hline $\mathrm{CO}$ & 10,286 & {$[\mathrm{~kg}]$} & 0,648 & Cetesb $(2009)$ \\
$\mathrm{CO}_{2}$ & 496,114 & {$[\mathrm{~kg}]$} & 31,255 & Cetesb $(2009)$ \\
$\mathrm{HC}$ & 37,714 & {$[\mathrm{~kg}]$} & 2,376 & Cetesb $(2009)$ \\
$\mathrm{NO}_{\mathrm{X}}$ & 257,143 & {$[\mathrm{~kg}]$} & 16,200 & Cetesb $(2009)$ \\
$\mathrm{SO}_{\mathrm{X}}$ & 12,686 & {$[\mathrm{~kg}]$} & 0,799 & Cetesb $(2009)$ \\
$\mathrm{MP}$ & $1.508,571$ & {$[\mathrm{~kg}]$} & 95,040 & Cetesb $(2009)$ \\
Água & $10.000,000$ & {$[\mathrm{~L}]$} & 630,000 & ETERNIT $(2013)$ \\
Energia & $1.934,400$ & {$[\mathrm{kWh}]$} & 121,900 & ETERNIT $(2013)$ \\
\hline
\end{tabular}

194 Marques, V. M.; Gomes, L. P.; Kern, A. P. 
Tabela 9 - Emissões na fase de fabricação das telhas de fibrocimento com polipropileno (Cenário 2)

\begin{tabular}{|c|c|c|c|c|}
\hline EMISSÃO/CONSUMO & VALOR MENSAL & UNIDADE & UNIDADE/UF & FONTE \\
\hline $\mathrm{CO}$ & 10,286 & {$[\mathrm{~kg}]$} & 0,873 & \multirow{6}{*}{$\begin{array}{c}\text { Cetesb } \\
\text { (COMPANHIA..., } \\
\text { 2009) }\end{array}$} \\
\hline $\mathrm{CO}_{2}$ & 496,114 & {$[\mathrm{~kg}]$} & 42,110 & \\
\hline $\mathrm{HC}$ & 37,714 & {$[\mathrm{~kg}]$} & 3,201 & \\
\hline $\mathrm{NO}_{\mathrm{x}}$ & 257,143 & {$[\mathrm{~kg}]$} & 21,826 & \\
\hline $\mathrm{SO}_{\mathrm{X}}$ & 12,686 & {$[\mathrm{~kg}]$} & 1,077 & \\
\hline MP & $1.508,571$ & {$[\mathrm{~kg}]$} & 128,048 & \\
\hline Água & $6.000,000$ & [L] & 509,300 & BRASILIT (2013) \\
\hline Energia & 405,000 & {$[\mathrm{kWh}]$} & 34,400 & BRASILIT (2013) \\
\hline
\end{tabular}

Tabela 10 - Cenário 1 (com amianto fabricado em Colombo, PR)

\begin{tabular}{c|c|c|c|r|r|r|r|r}
\hline $\begin{array}{c}\text { Emissão/ } \\
\text { Consumo }\end{array}$ & $\begin{array}{c}\text { Extração } \\
\text { Cimento }\end{array}$ & $\begin{array}{c}\text { Extração } \\
\text { Fibra }\end{array}$ & $\begin{array}{c}\text { Trans. } \\
\text { Cimento } \\
\text { (Mina-Fáb.) }\end{array}$ & $\begin{array}{c}\text { Transp. } \\
\text { Fibra } \\
\text { (Mina-Fáb.) }\end{array}$ & $\begin{array}{c}\text { Fabr. } \\
\text { Telha }\end{array}$ & $\begin{array}{c}\text { Transp. Telha } \\
\text { (Fáb.-Obra) }\end{array}$ & $\begin{array}{c}\text { Transp. Telha } \\
\text { (Obra-Aterro) }\end{array}$ & SOMA \\
\hline $\mathrm{CO}$ & 0,0 & 0,0 & 1,4 & 10,3 & 0,6 & 4,1 & 0,0 & 16,6 \\
$\mathrm{CO}_{2}$ & 668,9 & 0,0 & 69,1 & 496,5 & 31,3 & 198,7 & 1,4 & $1.465,9$ \\
$\mathrm{HC}$ & 0,0 & 0,0 & 0,7 & 5,2 & 2,4 & 2,1 & 0,0 & 10,4 \\
$\mathrm{NO}_{\mathrm{X}}$ & 1,9 & 0,0 & 5,0 & 36,2 & 16,2 & 14,5 & 0,1 & 74,0 \\
$\mathrm{SO}_{\mathrm{X}}$ & 1,3 & 0,0 & 0,2 & 1,6 & 0,8 & 0,6 & 0,0 & 4,5 \\
$\mathrm{MP}$ & 0,3 & 0,0 & 0,3 & 2,1 & 95,0 & 0,8 & 0,0 & 98,5 \\
Água & 101,5 & 0,0 & 0,0 & 0,0 & 630,0 & 0,0 & 0,0 & 731,5 \\
Energia & 111,7 & 308,6 & 0,0 & 0,0 & 121,9 & 0,0 & 0,0 & 542,1 \\
\hline
\end{tabular}

Tabela 11 - Quantificação das emissões por categoria de impacto ambiental no Cenário 1

\begin{tabular}{|c|c|c|c|c|c|c|}
\hline $\begin{array}{l}\text { Emissão/ } \\
\text { Consumo }\end{array}$ & SOMA & $\begin{array}{c}\text { Efeito } \\
\text { Estufa } \\
\text { (kg eq. } \\
\mathrm{CO}_{2} \text { ) } \\
\end{array}$ & $\begin{array}{l}\text { Chuva } \\
\text { Ácida (kg } \\
\left.\text { eq. } \mathrm{SO}_{2}\right)\end{array}$ & $\begin{array}{c}\text { Toxicidade } \\
\text { (kg eq. } \\
\text { tolueno) }\end{array}$ & $\begin{array}{c}\text { Consumo de } \\
\text { Energia } \\
(\mathbf{k W h})\end{array}$ & $\begin{array}{c}\text { Consumo } \\
\text { de Água } \\
\left(\mathbf{m}^{3}\right)\end{array}$ \\
\hline $\mathrm{CO}$ & 16,6 & 33,2 & 0,0 & 4,5 & 0,0 & 0,0 \\
\hline $\mathrm{CO}_{2}$ & $1.465,9$ & $1.465,9$ & 0,0 & 0,0 & 0,0 & 0,0 \\
\hline $\mathrm{HC}$ & 10,4 & 0,0 & 0,0 & 10,4 & 0,0 & 0,0 \\
\hline $\mathrm{NO}_{\mathrm{X}}$ & 74,0 & 0,0 & 51,8 & 318,1 & 0,0 & 0,0 \\
\hline $\mathrm{SO}_{\mathrm{X}}$ & 4,5 & 0,0 & 4,5 & 26,8 & 0,0 & 0,0 \\
\hline MP & 98,5 & 0,0 & 0,0 & 285,6 & 0,0 & 0,0 \\
\hline Água & 731,5 & 0,0 & 0,0 & 0,0 & 0,0 & 731,5 \\
\hline Energia & 542,1 & 0,0 & 0,0 & 0,0 & 542,1 & 0,0 \\
\hline \multicolumn{2}{|r|}{ TOTAL } & $1.499,2$ & 56,2 & 645,3 & 542,1 & 731,5 \\
\hline
\end{tabular}

Já nas Tabelas 12 e 13 consta o levantamento total do Cenário 2, que se refere à fabricação de telhas com polipropileno fabricadas em Esteio.

Observa-se que perante todas as categorias de impacto o Cenário 2, com polipropileno, apresenta menores valores. Na categoria de efeito estufa os resultados apontam que o Cenário 2 apresenta valor aproximadamente $19 \%$ menor, se comparado com Cenário 1, com amianto. Já quanto à ocorrência de chuvas ácidas, o Cenário 2 apresenta valores aproximadamente $30 \%$ inferiores na comparação com o Cenário 1 , e quanto à toxicidade humana a diferença é de aproximadamente $3 \%$ em favor do Cenário 2, com polipropileno. Ainda, se observarmos os valores referentes a consumo de energia e água, o Cenário 2 apresenta valores menores, respectivamente $70 \%$ e $12 \%$.

Já referente à técnica de Levantamento de Aspectos e Impactos Ambientais, utilizaram-se as três primeiras categorias de impactos ambientais além do uso de recursos não renováveis (matériaprima), risco à saúde e uso de energia e água. 
Tabela 12 - Cenário 2 (com polipropileno fabricado em Esteio, RS)

\begin{tabular}{c|c|c|c|c|c|c|c|r}
\hline $\begin{array}{c}\text { Emissão/ } \\
\text { Consumo }\end{array}$ & $\begin{array}{c}\text { Extração } \\
\text { Cimento }\end{array}$ & $\begin{array}{c}\text { Extração } \\
\text { Fibra }\end{array}$ & $\begin{array}{c}\text { Trans. } \\
\text { Cimento } \\
\text { (Mina-Fáb.) }\end{array}$ & $\begin{array}{c}\text { Transp. } \\
\text { Fibra } \\
\text { (Mina-Fáb.) }\end{array}$ & Fabr. Telha & $\begin{array}{c}\text { Transp. } \\
\text { Telha } \\
\text { (Fáb.-Obra) }\end{array}$ & $\begin{array}{c}\text { Transp. Telha } \\
\text { (Obra-Aterro) }\end{array}$ & SOMA \\
\hline $\mathrm{CO}$ & 0,0 & 0,0 & 0,1 & 7,4 & 0,9 & 0,1 & 0,0 & 8,5 \\
$\mathrm{CO}_{2}$ & 734,8 & 46,6 & 4,3 & 355,7 & 42,1 & 6,3 & 1,4 & $1.191,2$ \\
$\mathrm{HC}$ & 0,0 & 0,0 & 0,0 & 3,7 & 3,2 & 0,1 & 0,0 & 7,0 \\
$\mathrm{NO}_{\mathrm{X}}$ & 2,1 & 0,1 & 0,3 & 25,9 & 21,8 & 0,5 & 0,1 & 50,9 \\
$\mathrm{SO}_{\mathrm{X}}$ & 1,4 & 0,0 & 0,0 & 1,1 & 1,1 & 0,0 & 0,0 & 3,6 \\
$\mathrm{MP}$ & 0,3 & 0,0 & 0,0 & 1,5 & 128,0 & 0,0 & 0,0 & 129,9 \\
Água & 0,0 & 0,8 & 0,0 & 0,0 & 0,0 & 0,0 & 0,0 & 0,8 \\
Energia & 0,0 & 0,1 & 0,0 & 0,0 & 0,0 & 0,0 & 0,0 & 0,1 \\
\hline
\end{tabular}

Tabela 13 - Quantificação das emissões por categoria de impacto ambiental no Cenário 2

\begin{tabular}{c|r|r|r|r|r|r}
\hline $\begin{array}{c}\text { Emissão/ } \\
\text { Consumo }\end{array}$ & SOMA & $\begin{array}{c}\text { Efeito Estufa } \\
\text { (kg eq. } \mathbf{C O}_{\mathbf{2}} \text { ) }\end{array}$ & $\begin{array}{c}\text { Chuva Ácida } \\
\text { (kg eq. } \mathbf{S O}_{\mathbf{2}} \text { ) }\end{array}$ & $\begin{array}{c}\text { Toxicidade (kg } \\
\text { eq. tolueno) }\end{array}$ & $\begin{array}{c}\text { Consumo de } \\
\text { Energia }(\mathbf{k W h})\end{array}$ & $\begin{array}{c}\text { Consumo de } \\
\text { Água }\left(\mathbf{m}^{\mathbf{3}}\right)\end{array}$ \\
\hline $\mathrm{CO}$ & 8,5 & 17,1 & 0,0 & 2,3 & 0,0 & 0,0 \\
$\mathrm{CO}_{2}$ & $1.191,2$ & $1.191,2$ & 0,0 & 0,0 & 0,0 & 0,0 \\
$\mathrm{HC}$ & 7,0 & 0,0 & 0,0 & 7,0 & 0,0 & 0,0 \\
$\mathrm{NO}_{\mathrm{X}}$ & 50,9 & 0,0 & 35,6 & 218,7 & 0,0 & 0,0 \\
$\mathrm{SO}_{\mathrm{X}}$ & 3,6 & 0,0 & 3,6 & 21,7 & 0,0 & 0,0 \\
$\mathrm{MP}$ & 129,9 & 0,0 & 0,0 & 376,7 & 0,0 & 0,0 \\
Água & 637,4 & 0,0 & 0,0 & 0,0 & 0,0 & 637,4 \\
Energia & 160,8 & 0,0 & 0,0 & 0,0 & 160,8 & 0,0 \\
\hline \multicolumn{7}{r}{} \\
\hline
\end{tabular}

Quanto ao uso de recursos naturais não renováveis foram observados os valores apresentados na Tabela 1, sendo o menor valor $1.260 \mathrm{~kg}$, considerado $100 \%$, e o maior $1.273 \mathrm{~kg}, 101,05 \%$. Em relação à categoria riscos à saúde, consideraram-se as informações das Fichas de Informação de Segurança de Produtos Químicos (FISPQ) dos materiais utilizados na fabricação das telhas.

Tais FISPQ são documentos normalizados pela ABNT e têm como função divulgar as informações importantes sobre as medidas de proteção e cuidado que devem ser adotados no manuseio e transporte desses tipos de produtos químicos. Esses documentos devem ser disponibilizados pela empresa que os comercializa e são obrigatórios para a comercialização de tais produtos. Cada critério analisado em uma FISPQ é avaliado e é atribuído um valor entre 0 e 4 , sendo 0 classificado como não perigoso e 4 como extremamente perigoso.
Os dados referentes às FISPQ dos materiais analisados estão nas Tabelas 14 e 15.

\section{Conclusões}

Na Tabela 16 juntaram-se na mesma planilha os resultados do ACV e do Laia. Embora não se faça o somatório dos impactos medidos em cada cenário para cada categoria, pretendeu-se aqui facilitar a visualização completa da avaliação realizada.

Assim, definiu-se o Cenário 1 (com amianto) como o referencial, portanto todos os resultados obtidos foram computados como 100\%. Em comparação, calculou-se a diferença, para cada categoria, dos resultados obtidos no Cenário 2, com polipropileno.

Em paralelo à Tabela 16, os mesmos valores são apresentados na Figura 2, na forma de gráfico de barras, para melhor visualização e comparação dos valores. 
Tabela 14 - Riscos à saúde (telha com amianto)

\begin{tabular}{|c|c|c|c|c|c|c|c|c|}
\hline \multicolumn{2}{|c|}{ TELHA COM AMIANTO } & \multicolumn{4}{|c|}{ CRITÉRIOS DE SEGURANÇA } & \multirow{2}{*}{$\begin{array}{l}\text { Soma dos } \\
\text { critérios }\end{array}$} & \multirow{2}{*}{$\begin{array}{c}\text { Riscos } \\
\text { à } \\
\text { saúde }\end{array}$} & \multirow{2}{*}{$\begin{array}{l}\text { Valor } \\
\text { Final }\end{array}$} \\
\hline Material & kg & $\%$ & $\begin{array}{c}\text { Riscos à } \\
\text { Saúde }\end{array}$ & $\begin{array}{c}\text { Inflamabili- } \\
\text { dade }\end{array}$ & $\begin{array}{l}\text { Reativi- } \\
\text { dade }\end{array}$ & & & \\
\hline Cimento hidratado & 1.015 & 80,56 & 1 & 0 & 0 & 1 & $\bar{S}$ & 80,5 \\
\hline Amianto & 160 & 12,70 & 4 & 0 & 0 & 4 & S & 50,8 \\
\hline Celulose & 5 & 0,40 & 0 & 0 & 0 & 0 & $\mathrm{~N}$ & 0,0 \\
\hline Cinza volante & 47 & 3,73 & 1 & 0 & 1 & 2 & $\mathrm{~S}$ & 7,5 \\
\hline Enchimento (Areia) & 33 & 2,62 & 0 & 0 & 0 & 0 & $\mathrm{~N}$ & 0,0 \\
\hline Risco total & & & & & & & & 138,8 \\
\hline
\end{tabular}

Tabela 15 - Riscos à saúde (telha com polipropileno)

\begin{tabular}{|c|c|c|c|c|c|c|c|c|}
\hline \multicolumn{2}{|c|}{$\begin{array}{c}\text { TELHA COM } \\
\text { POLIPROPILENO }\end{array}$} & \multicolumn{4}{|c|}{ CRITÉRIOS DE SEGURANÇA } & \multirow{2}{*}{$\begin{array}{l}\text { Soma dos } \\
\text { critérios }\end{array}$} & \multirow{2}{*}{$\begin{array}{c}\text { Riscos } \\
\text { à } \\
\text { saúde }\end{array}$} & \multirow{2}{*}{$\begin{array}{l}\text { Valor } \\
\text { Final }\end{array}$} \\
\hline Material & kg & $\%$ & $\begin{array}{l}\text { Riscos à } \\
\text { Saúde }\end{array}$ & $\begin{array}{c}\text { Inflamabili } \\
\text { dade }\end{array}$ & $\begin{array}{c}\text { Reativida } \\
\text { de }\end{array}$ & & & \\
\hline Cimento hidratado & 1.115 & 87,57 & 1 & 0 & 0 & 1 & $S$ & 87,6 \\
\hline $\mathrm{PP}$ & 28 & 2,20 & 1 & 0 & 0 & 1 & $\mathrm{~S}$ & 2,2 \\
\hline Carbonato de cálcio & 14,9 & 1,17 & 1 & 0 & 1 & 2 & $S$ & 2,3 \\
\hline Celulose & 35 & 2,75 & 0 & 0 & 0 & 0 & $\mathrm{~N}$ & 0,0 \\
\hline Cinza volante & 3,5 & 0,27 & 1 & 0 & 1 & 2 & $\mathrm{~S}$ & 0,6 \\
\hline Sílica amorfa & 73,5 & 5,77 & 1 & 0 & 1 & 2 & $\mathrm{~S}$ & 11,6 \\
\hline Fita de segurança & 2,6 & 0,20 & 0 & 0 & 0 & 0 & $\mathrm{~N}$ & 0,0 \\
\hline Floculante & 0,3 & 0,02 & 3 & 0 & 3 & 6 & $\mathrm{~S}$ & 0,1 \\
\hline Agente antiespumante & 0,4 & 0,03 & 1 & 0 & 0 & 1 & $S$ & 0,0 \\
\hline Risco total & & & & & & & & 104,4 \\
\hline
\end{tabular}

Tabela 16 - Comparativo perante as categorias

\begin{tabular}{|c|c|c|c|c|c|}
\hline \multirow[t]{2}{*}{ CATEGORIAS } & \multirow[t]{2}{*}{ Unidade } & \multicolumn{2}{|c|}{$\begin{array}{c}\text { CENÁRIO } 1 \\
\text { (com Amianto) }\end{array}$} & \multicolumn{2}{|c|}{$\begin{array}{c}\text { CENÁRIO } 2 \\
\text { (com PP) }\end{array}$} \\
\hline & & kg & $\%$ & kg & $\%$ \\
\hline Uso de recursos naturais & $\mathrm{kg}$ recursos naturais na UF & $1.260,0$ & 100,00 & $1.273,2$ & 101,05 \\
\hline Riscos à saúde (FISPQ) & $\begin{array}{l}\text { Materiais maléficos em sua } \\
\text { composição multiplicada pelos } \\
\text { critérios de segurança }\end{array}$ & 138,8 & 100,00 & 104,4 & 75,20 \\
\hline Efeito estufa & kg eq. de $\mathrm{CO}_{2}$ & $1.499,2$ & 100,00 & $1.208,3$ & 80,60 \\
\hline Acidificação & kg eq. de $\mathrm{SO}_{2}$ & 56,2 & 100,00 & 39,2 & 69,74 \\
\hline Toxicidade humana & $\mathrm{kg}$ eq. de tolueno & 645,3 & 100,00 & 626,5 & $\mathbf{9 7 , 0 7}$ \\
\hline Consumo de energia & kwh & 542,1 & 100,00 & 160,8 & 29,65 \\
\hline Consumo de água & $\mathrm{m}^{3}$ & 731,5 & 100,00 & 637,4 & 87,14 \\
\hline
\end{tabular}


Figura 2 - Gráfico comparativo perante as categorias avaliadas

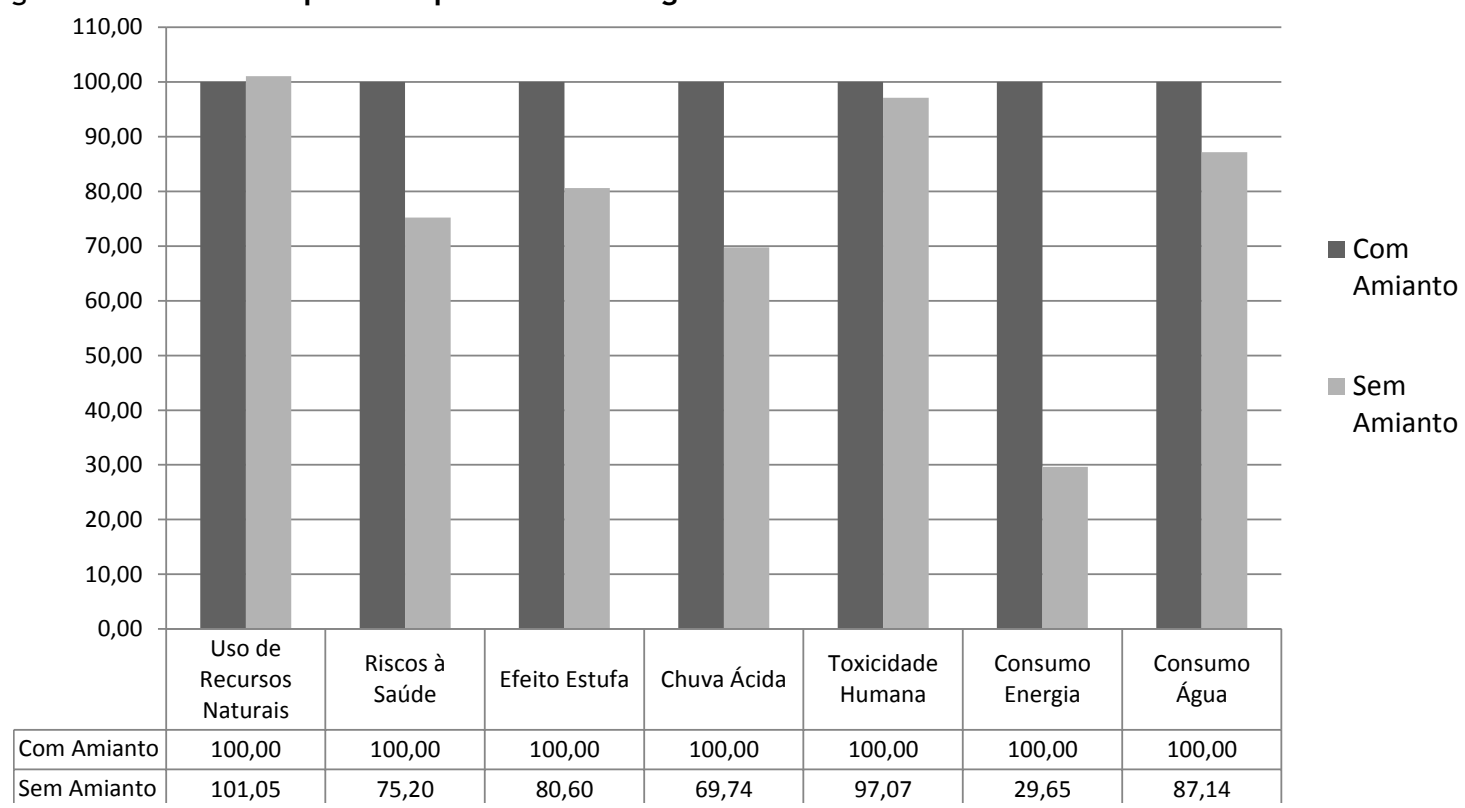

Assim, se o resultado no Cenário 2 foi maior que o $100 \%$ do Cenário 1, analisou-se que a categoria de impacto avaliado foi mais mal avaliada neste cenário em comparação ao outro. Por exemplo, na categoria "uso de recursos naturais" o Cenário 2 apresentou valor maior na avaliação, ou seja, com o emprego de polipropileno houve utilização maior de recursos naturais do que no processo em que a telha é fabricada com amianto, portanto situação pior em relação à avaliação ambiental. Por outro lado, na categoria "risco à saúde" o Cenário 2 resultou em valor menor $(75,20 \%)$ do que o $100 \%$ do Cenário 1. Avalia-se, neste caso, que as telhas com amianto trazem maior risco à saúde do que as telhas com polipropileno.

Vale salientar que grande parte dos dados utilizados para esta avaliação foi coletada em trabalhos distintos, em que, algumas vezes, se fizeram necessárias aproximações de valores e semelhança entre materiais distintos. Tal fato teve como intuito preencher lacunas da literatura, fazendo com que esta avaliação pudesse ser realizada. Trabalhos futuros, com determinação in loco das emissões e gerações resultantes dos processos envolvidos, deverão ser realizados de forma a confirmarem-se os resultados ora apresentados.

Ao final, observando-se a pontuação obtida por cada cenário perante cada categoria, o Cenário 2, com polipropileno, foi mais vantajoso em seis categorias: riscos à saúde, efeito estufa, chuva ácida, toxicidade humana, consumo de água e consumo de energia. Já o Cenário 1 obteve índices melhores apenas na categoria de uso de recursos naturais. Confirma-se assim que o uso de amianto é mais desfavorável que o uso de polipropileno, sob o foco ambiental.

Observa-se, então, que a substituição das fibras de amianto pelas de polipropileno, segundo a ACV e o Laia, efetivamente diminui os impactos ambientais negativos, sobretudo perante as categorias de riscos à saúde, efeito estufa e chuva ácida, contudo agrega outros efeitos negativos, tais como aumento de recursos naturais envolvidos no processo. Se este último aspecto é hoje uma das grandes preocupações mundiais, há de se avaliar se a substituição realizada com esse tipo de fibra estudada é a mais adequada. $\mathrm{O}$ que se pode sugerir é que novos estudos busquem materiais e processos que reduzam as emissões e, portanto, os problemas de saúde, mas também que sejam obtidos através de processos mais limpos, com menor uso de recursos naturais, possibilitando a reutilização de resíduos com menor consumo de água e energia.

\section{Referências}

ASSOCIAÇÃO BRASILEIRA DE NORMAS TÉCNICAS. NBR 14001: sistemas de gestão ambiental: requisitos com orientações para uso. Rio de Janeiro, 2004.

ASSOCIAÇÃO BRASILEIRA DE NORMAS TÉCNICAS. NBR 14040: gestão ambiental: avaliação do ciclo de vida: princípios e estrutura. Rio de Janeiro, 2009a. 
ASSOCIAÇÃO BRASILEIRA DE NORMAS TÉCNICAS. NBR 14044: gestão ambiental: avaliação do ciclo de vida: requisitos e orientações. Rio de Janeiro, 2009b.

\section{ASSOCIAÇÃO BRASILEIRA DO CIMENTO} PORTLAND. Emissões do Concreto. Disponível em:

<http://www.abcp.org.br/conteudo/imprensa/indust ria-do-cimento-brasileira-e-a-mais-ecoeficientedo-mundo>. Acesso em: 14 ago. 2013.

\section{ASSOCIAÇÃO BRASILEIRA DOS EXPOSTOS AO AMIANTO. História do Amianto. \\ Disponível em: \\ <http://www.abrea.com.br/06historia.htm>. Acesso em: 11 jan. 2013.}

ADAMS, K. et al. Development of Emission Factors for Polypropylene Processing. Journal of the Air \& Waste Management Association, v. 49, p. 49-56, 1999.

AGOPYAN, V.; JOHN, V. M. O Desafio da Sustentabilidade na Construção Civil. São Paulo: Blücher, 2011.

ARAUJO, M. G. Modelo de Avaliação do ciclo de Vida Para a Gestão de Resíduos de Equipamentos Eletroeletrônicos no Brasil. Rio de Janeiro, 2013. 217 f. Tese (Doutorado em Ciências) - Universidade Federal do Rio de Janeiro, Rio de Janeiro. 2013.

BRASIL. Lei $\mathbf{n}^{\mathbf{0}} \mathbf{1 2 . 3 0 5}$, de 2 de agosto de 2010 . Disponível em: <http://www.planalto.gov.br/ccivil_03/_ato20072010/2010/lei/112305.htm>. Acesso em: 14 jan. 2013.

CAMARGO, A. M. Inventário do Ciclo de Vida do Metanol Para as Condições Brasileiras. 2007. 117 f. Dissertação (Mestrado em Engenharia Química) - Escola de Química, Universidade de São Paulo, São Paulo, 2007.

\section{COMPANHIA ENERGÉTICA DE MINAS} GERAIS. Inventário de Gases de Efeito Estufa 2012. Disponível em: $<$ http://www.cemig.com.br/pt-

br/A_Cemig_e_o_Futuro/sustentabilidade/nossos_ programas/mudancas_climaticas/Documents/relat \%C3\%93rio invent\%C3\%81rio cemig - 2012 portugu\%C3\%8as - final - 0805 2013.pdf>. Acesso em: 24 set. 2013.

COMPANHIA AMBIENTAL DO ESTADO DE SÃO PAULO. Inventário de Emissões das Fontes Estacionárias do Estado de São Paulo. 2009. Disponível em: <http://sistemasinter.cetesb.sp.gov.br/inventariofo ntes/Manual_de_Preenchimento.pdf $>$, Acesso em: 19 out. 2013.
CHEN, C. et al. On-Road Emission Characteristics of Heavy-Duty Diesel Vehicles in Shanghai.

Atmospheric Environment, v. 41, n. 26, p. 53345344, 2007.

CHINA. Ministry of Environmental Protection of the People's Republic of China. Vehicle Emission Control Annual Report. 2010. Disponível em: <http://www.vecc-mep.org.cn/news/ e_home_gg/2010engreport.pdf $>$, Acesso em: 10 mar. 2013.

CLAUDINO, E. S.; TALAMINI, E. Análise do Ciclo de Vida (ACV) Aplicada ao Agronegócio. Revista Brasileira de Engenharia Agrícola e Ambiental, v. 17, n. 1, p. 77-85, 2013.

COMISSÃO DE MEIO AMBIENTE E DESENVOLVIMENTO SUSTENTÁVEL.

Dossiê. Disponível em:

<http://www.mma.gov.br/port/conama/processos/1 8018FE8/DossieAmianto Brasil 2010.pdf>, Acesso em: 19 fev. 2013.

CONSELHO NACIONAL DO MEIO

AMBIENTE. Resolução Conama no 307, de 5 de julho de 2002. Disponível em:

<http://www.mma.gov.br/port/conama/legiabre.cf m?codlegi=307>, Acesso em: 23 out. 2012.

COSTA, G. C. F. Uma Avaliação do Consumo de Energia Com Transportes em Cidades do Estado de São Paulo. São Paulo, 2001. 103 f. Dissertação (Mestrado em Engenharia Civil) Escola de Engenharia, Universidade de São Paulo, São Paulo, 2001.

\section{ECOINVENT CENTRE. Ecoinvent database} v3.01. Swiss Centre for Life Cycle Inventories, Dubendorf, 2013. Disponível em: <https://ecoquery.ecoinvent.org/Details/UPR/5903 eb36-5412-4c1d-aa4c-b8012a6f3fc8/8b738ea0f89e-4627-8679-433616064e82>. Acesso em: 06 ago. 2015.

ETERNIT. Informações Sobre Produção. Disponível em: <http://www.eternit.com.br>. Acesso em: 19 jun. 2013.

BRASILIT. Amianto. Disponível em: <http://www.brasilit.com.br/meioambiente/amianto.php>. Acesso em: 10 fev. 2013.

FAUSTINO, F. Os Prós e Contras do Uso do Amianto no Brasil. Disponível em: <http://rmai.com.br/v4/Read/1139/os-pros-econtras-do-uso-do-amianto-no-brasil.aspx $>$. Acesso em: 10 ago. 2013.

FORSTER, P. et al. Changes in Atmospheric Constituents and in Radiative Forcing. In: CLIMATE Change 2007: The Physical Science Basis. Cambridge: IPCC Intergovernmental Panel on Climate Change, 2007. 
FRANCO, V. et al. Road Vehicle Emission Factors Development: a review. Atmospheric Environment, v. 70, p. 84-97, 2013.

FRAZÃO, R.; FERNANDES, R. Análise Comparativa do Ciclo de Vida de Fibrocimento AT e Fibrocimento NT. 2004. Disponível em: <http://www.crisotilabrasil.org.br/site/pesquisas/_p df/Analise ciclo vida.pdf $>$. Acesso em: $14 \mathrm{fev}$. 2013.

GARCIA, J. C. C.; SPERLING, E. V. Emissão de Gases de Efeito Estufa no Ciclo de Vida do Etanol: estimativa nas fases de agricultura e industrialização em Minas Gerais. Engenharia Sanitária Ambiental, v. 15, n. 3, p. 217-222, 2010.

GHK Holdings Limited. A Study to Examine the Benefits of the End of Life Vehicles Directive and the Costs and Benefits of a Revision of the 2015 Targets For Recycling, Re-Use and Recovery Under the ELV Directive: final report to DG environment. 2006. Disponível em: <http://ec.europa.eu/environment/waste/pdf/study/ final_report.pdf $>$ Acesso em: 9 out. 2013.

HAUSBERGER, M. R. S. et al. Heavy Duty Vehicle Emissions Final Report: assessment and reliability of transport emission models and inventory systems. 2005. Disponível em: <http://www.inrets.fr/ur/lte/publiautresactions/fichesresultats/ficheartemis/road3/mo delling33/Artemis_del4_HDV.pdf>. Acesso em: 19 mar. 2013.

HEALTH EFFECTS INSTITUTE. Asbestos Research. Asbestos in Public and Commercial Buildings. 1991. Disponível em: <http://pubs.healtheffects.org/view.php?id=13>. Acesso em: 21 jun. 2013.

HERTWICH, E. G. et al. An Update of the Human Toxicity Potential With Special Consideration of Conventional Air Pollutants. 2006. Disponível em: <http://ntnu.divaportal.org/smash/get/diva2:121810/FULLTEXT01 .pdf>. Acesso em: $11 \mathrm{dez} .2013$.

HUET, H. Propriedades do Amianto. Disponível em: <http://www.fuguitang.com/propriedades-deamianto.html>. Acesso em: 10 ago. 2013.

\section{INTERNATIONAL ORGANIZATION FOR} STANDARDIZATION. ISO/TR 14047:

environmental management: life cycle assessment: illustrative examples on how to apply ISO 14044 to impact assessment situations. Geneve, 2012a.

INTERNATIONAL ORGANIZATION FOR STANDARDIZATION. ISO/TS 14048: environmental management: life cycle assessment: data documentation format. Geneve, 2002.
INTERNATIONAL ORGANIZATION FOR STANDARDIZATION. ISO/TR 14049:

environmental management: life cycle assessment: illustrative examples on how to apply ISO 14044 to goal and scope definition and inventory analysis. Geneve, 2012b.

LIMA, A. R. D. E. Avaliação das Conseqüências da Produção de Concreto no Brasil Para as Mudanças Climáticas. São Paulo, 2010. 129 f. Tese (Doutorado em Engenharia Civil) - Escola de Engenharia, Universidade de São Paulo, São Paulo, 2010.

MADLOOL, N. A. et al. A Critical Review on Energy Use and Savings in the Cement Industries. Renewable and Sustainable Energy Reviews, v. 15, n. 4, p. 2042-2060, 2011.

MARQUES, V. M. Avaliação de Aspectos e Impactos Ambientais ao Longo do Ciclo de Vida de Telhas de Fibrocimento Com e Sem Amianto. São Leopoldo, 2014. 132 f. Dissertação (Mestrado em Engenharia Civil) - Programa de Pós-Graduação em Engenharia Civil, Universidade do Vale do Rio dos Sinos, São Leopoldo, 2014.

MENDES, R. Asbesto (Amianto) e Doença: revisão do conhecimento científico e fundamentação para uma urgente mudança da atual política brasileira sobre a questão. Cadernos de Saúde Pública, Rio de Janeiro, v. 17 n. 1 p. 7-29, jan-fev 2001.

MIRANDA, L. F. R.; ANGULO, S. C.; CARELI, E. D. A Reciclagem de Resíduos de Construção e Demolição no Brasil: 1986-2008. Revista

Ambiente Construído, Porto Alegre, v. 9, n. 1, p. 57-71, jan./mar. 2009.

NASCIMENTO, M. D. do. Otimização do Uso de Lenha e Cavaco de Madeira para Produção de Energia em Agroindústria Seropédica.

Botucatu, 2007. 103 f. Dissertação (Mestrado em Agronomia) - Faculdade de Agronomia, Universidade Estadual Paulista Julio De Mesquita Filho, Botucatu, 2007.

NEIVA, S.; MATEUS, R.; BRAGANÇA, L. Utilização do Método LCA no Projeto de Edifícios Sustentáveis. In: CONGRESSO NACIONAL DA CONSTRUÇÃO, 4., Coimbra, 2012. Anais... Coimbra, 2012.

ORTIZ, O.; PASQUALINO, J. C.; CASTELLS, F. Environmental Performance of Construction Waste: comparing three scenarios from a case study in Catalonia, Spain. Waste Management, v. 30, n. 4, p. 646-54, 2010. 
PASCUAL-GONZÁLEZ, J. et al. Statistical Analysis of the Ecoinvent Database to Uncover Relationships Between Life Cycle Impact Assessment Metrics, Spain. Journal of Cleaner Production, p. 1-10, 2015.

PLASTICSEUROPE. Association of Plastics Manufacturers. Polypropylene (PP): environmental product declarations of the european plastics manufacturers. Bruxelas, Bélgica. 2008. Disponível em: <http://www.afvalmanager.nl/epd2.pdf >. Acesso em: 20 abr. 2015.

PYE, A. M. A Review of Asbestos Substitute Materials in Industrial Applications. Journal of Hazardous Materials, v. 3, p. 125-147, 1979.

SCLIAR, C. Amianto, Mineral Mágico ou Maldito? Ecologia humana e disputa políticoeconômica. Belo Horizonte: CDI, 1998.

SILVA, E.; ESTRELA, M. Alternativas Para a Valorização de Resíduos de Equipamentos Eléctricos e Electrónicos: a reutilização de componentes electrónicos segundo uma abordagem de avaliação de Ciclo de Vida. In: Congresso Nacional de Engenharia do Ambiente, 11., Lisboa, 2011. Anais... Lisboa, 2011.

TERRA FILHO, M.; BAGATIN, E. Exposição Ambiental ao Asbesto: avaliação do risco e efeitos na saúde. 2010. 176 f. Relatório Técnico. Projeto Asbesto Ambiental. São Paulo.

TOSTA, L. I.; SOUZA, A. C. de; SILVA, R. J. da. Gestão da Energia na Produção de Cimento Portland Com Uso de Mineralizadores e Combustíveis Alternativos. In: ENCONTRO NACIONAL DE ENGENHARIA DE PRODUÇÃO, 27., Foz do Iguaçu, 2007. Anais... Foz do Iguaçu, 2007.
UNITED STATES GEOLOGICAL SURVEY. Mineral Commodity Summaries 2013. 2013. Disponível em: <http://minerals.usgs.gov/minerals/pubs/mcs/2013/ mcs2013.pdf>. Acesso em: 15 set. 2013.

VAZQUEZ, E. Aplicación de Nuevos Materiales Reciclados en la Construcción Civil. In: SEMINÁRIO DE DESENVOLVIMENTO SUSTENTÁVEL E A RECICLAGEM NA CONSTRUÇÃO CIVIL, São Paulo, 2001. Anais... São Paulo, 2001.

VCIMENTOS. Votorantim Cimentos. Disponível em: <http://www.vcimentos.com.br/htmsptb/Responsabilidade/MonitoramentoEmissoes.ht m>. Acesso em: 14 ago. 2013.

VIEIRA, G. L. Estudo do Processo de Corrosão Sob a Ação de Íons Cloreto em Concretos Obtidos a Partir de Agregados Reciclados de Resíduos de Construção e Demolição. $150 \mathrm{f}$. Porto Alegre, 2003. Dissertação (Mestrado em Engenharia Civil) - Escola de Engenharia, Universidade Federal do Rio Grande do Sul, Porto Alegre, 2003.

XIANG, Q. et al. Effects of Melt Reprocessing on Volatile Emissions and Structural-Rheological Changes of Unstabilized Polypropylene. Polymer Degradation and Stability, v. 77, p. 93-102, 2002.

Vinicius Martins Marques

Programa de Pós-Graduacão em Engenharia Civil | Universidade do Vale do Rio dos Sinos | Av. Unisinos, 950, Cristo Rei | São Leopoldo RS - Brasil | Caixa Postal 275 | CEP 93022-000 | Tel.: (51) 3590-8464 | E-mail: vini1309@gmail.com

Luciana Paulo Gomes

Programa de Pós-Graduação em Engenharia Civil | Universidade do Vale do Rio dos Sinos | E-mail: lugomes@unisinos.br

Andrea Parisi Kern

Programa de Pós-Graduação em Engenharia Civil | Universidade do Vale do Rio dos Sinos | Tel.: (51) 3590-8766 |

E-mail: apkern@unisinos.br

Revista Ambiente Construído

Associação Nacional de Tecnologia do Ambiente Construído

Av. Osvaldo Aranha, $99-3^{\circ}$ andar, Centro

Porto Alegre - RS - Brasil

CEP 90035-190

Telefone: +55 (51) 3308-4084

Fax: +55 (51) 3308-4054

www.seer.ufrgs.br/ambienteconstruido

E-mail: ambienteconstruido@ufrgs.br 